Kansas State University Libraries

New Prairie Press

Conference on Applied Statistics in Agriculture 2000 - 12th Annual Conference Proceedings

\title{
UNCERTAINTY ANALYSIS OF A PIPE MODEL BASED ON CORRELATED DISTRIBUTIONS
}

Shoufan Fang

George Z. Gertner

Follow this and additional works at: https://newprairiepress.org/agstatconference

Part of the Agriculture Commons, and the Applied Statistics Commons

\section{(c) $($ ) $(9)$}

This work is licensed under a Creative Commons Attribution-Noncommercial-No Derivative Works 4.0 License.

\section{Recommended Citation}

Fang, Shoufan and Gertner, George Z. (2000). "UNCERTAINTY ANALYSIS OF A PIPE MODEL BASED ON CORRELATED DISTRIBUTIONS," Conference on Applied Statistics in Agriculture. https://doi.org/10.4148/ 2475-7772.1250

This is brought to you for free and open access by the Conferences at New Prairie Press. It has been accepted for inclusion in Conference on Applied Statistics in Agriculture by an authorized administrator of New Prairie Press. For more information, please contact cads@k-state.edu. 


\title{
UNCERTAINTY ANALYSIS OF A PIPE MODEL BASED ON CORRELATED DISTRIBUTIONS
}

\author{
Shoufan Fang and George Z. Gertner \\ Research Programmer and Professor of Biometrics \\ Department of Natural Resources and Environmental Sciences \\ University of Illinois at Urbana-Champaign, \\ Urbana, IL 61801.
}

\begin{abstract}
Traditionally, uncertainty analysis of complex simulation models has been conducted based on the assumption of that the components of the model are independent. In practice, correlation is universal in ecosystems. This study applied Bayesian estimation and rejection sampling to generate correlated random samples for an uncertainty analysis of a process based forest growth model, a pipe model. Comparison of error budgets built using independent and correlated distributions shows that correlated distributions are very important to provide reasonable and realistic simulation and uncertainty analysis.
\end{abstract}

\section{Introduction}

Variation in the outcome of model simulation is termed as "uncertainty" (Cox, 1977; Gertner, 1987). Uncertainty analysis of a model includes both variance analysis and sensitivity coefficient analysis (Cox, 1977; Fang, 2000; Gertner, 1987; Sobol, 1993). The variance distribution and sensitivity coefficients of a model can reflect the properties of the model and the reliability of its predictions. The behaviors and the variance contribution of the model components (including both variables and parameters of a model) are used to assess the properties of the model and the quality of simulation, and thus to improve the quality of model simulation.

Model assessment analyzes the properties and behaviors of a model at the levels of both the whole model and individual components (Cox, 1977; Fang, 2000; Gertner, 1987; Jansen et al., 1994; Rossing et al., 1994). The assessment at the level of individual components is usually based on the uncertainty behavior of a model caused by each component. Sensitivity analysis investigates the significance of the magnifying effect of each component but does not discuss the variance contribution of each component. Error budget analysis, which is one of the variance contribution analysis methods, concerns both the variation of the components and their magnifying effect (Gardner et al., 1990; Gertner, 1987, 1991; Gertner et al., 1996). Error budgets of process models allow us to partition the uncertainty (estimation error) in model projections caused by propagation of uncertainty in model inputs (Fang, 2000; Gertner, 1987; Gertner et al., 1996). More specifically, it is a catalog that displays the systematic partitioning of the contribution of different sources of error. By showing the effect of individual errors and groups 
of errors on the projection of multi-component models, error budgets allow us to assess the influence of different sources of uncertainty on the quality of those projections.

In uncertainty analysis, many methods have been developed for different types of models and systems (Cox, 1977; Downing et al., 1985; Fang, 2000; Gardner et al., 1990; Gertner, 1987; Gertner et al., 1996; Jansen et al., 1994; Keesman and Straten, 1990; Matsumoto et al., 1994; Morris 1991; Mowrer and Frayer, 1986; Noor et al., 1994; Rossing et al., 1994; Sarma et al., 1993; Sobol, 1993; Summers et al., 1993). Most of these methods do not consider correlation among model components. Independence is ether explicitly stated or implied. One important explanation is that when most of these methods were developed, estimation methods could not provide correlated joint distribution of model components. As computational Bayesian estimation methods have been developed, it is now possible to estimate and generate correlated joint distributions of model components (Fang, 2000; Gertner et al., 1999). In order to adapt to this progress in terms of uncertainty analysis, Fang (2000) developed an improved Monte Carlo method for building error budgets based on correlated joint distribution of model components.

The pipe model, a mechanistic forest growth model, has been developed based on the pipe theory, self-thinning rule, and carbon-balance (Valentine, 1985 and 1988). It has been used in the monitoring, simulation, and projection of dynamics of forest ecosystems (Gertner et al. 1996; Gertner et al. 1999). Gertner et al. (1996) have built error budgets of the pipe model based on mutually-independent model components for red pine (Pinus resinosa Ait.) growing in the Great Lakes region of North America.

The purpose of this paper is to briefly report on a study where rejection Bayesian sampling and an improved Monte Carlo method for building error budgets were used for a pipe model calibrated for Norway spruce (Picea arbies Karst) in Denmark. The error budgets were developed and compared for the cases where the joint distributions were assumed independent and correlated.

\section{Methodology}

\section{Model description}

The pipe model is a multiresponse nonlinear iterative model. There are three responses (state variables) in the model: basal area (BA), pipe length (PL, which can be represented by average dominant height), and total volume (TV). There are 20 physiological and scaling parameters in the model. Most of these parameters are shared by all state variables. Since the components of this model relate to realistic ecosystems, all the components of the pipe model have also been called entities (Gertner et al., 1996). The structure of the pipe model has been described in Fang (2000), Gertner et al. (1999), and Valentine (1988). Valentine (1985 and 1988) and Gertner et al. (1996) defined the model components (Table 1).

\section{Data}

Observations of Norway spruce stands were collected from 14 thinning experiments in even-aged Norway spruce in Denmark (Skovsgaard, 1997). All plots were of the same quality: their site index for Norway spruce were all 25 (meters). The plots were all unthinned control plots and they were remeasured at regular time intervals through their entire rotation. An observation on the plot included age, BA (basal area), PL (pipe length), and TV (total volume) of a plot. Fang (2000) described the details of calculating BA and TV from the original 
measurement based on studies of Madsen and Heusèrr (1993) and Hakkila (1989). The simple statistics of state variables are listed in Table 2 and the initial state variables estimated using observations were listed in the first 3 rows of Table 3.

Random number generation

Fang (2000) and Gertner et al. (1999) had developed parameter estimation methods for multiresponse nonlinear models based on rejection Bayesian sampling. This study applies the developed rejection Bayesian sampling method to generate random sample for simulation and building error budgets of the pipe model.

Simulation Setting

Two Monte Carlo simulations were conducted in building error budgets of the pipe model. One is based on correlated distribution of the model components and the other is based on independent distributions.

In the simulation with correlated distributions, the prior distributions of model components for rejection Bayesian sampling were truncated normal distributions. It was assumed for the priors that there was no dependence among the marginals of model components. In the simulation with independent distributions, probabilities of model components were also assumed to be truncated normal distributions (Table 3). The mean vector of independent distribution was adapted from the posterior of rejection Bayesian estimation. The distribution of the initial state variables (BA, PL, and TV) was estimated using the observations of the Norway spruce stands measured from ages 28 and 32 years. The pipe model was used to project growth of the forest stand to the age of 60 years. The outputs of simulations at age 60 were used in building error budgets. The random sample size was of 30,000 random vectors. More explicit details about the simulation settings can be found in Fang (2000).

\section{Error Budget Building}

Fang (2000) improved the Monte Carlo method to build error budgets based on correlated distributions of the model components (see Appendix). The process to generate random samples and build error budgets is described in Figure 1. Derivation and properties of the method can be found in Fang (2000).

In built error budgets, overall variance is the variance obtained directly from simulation. Total variance is the summation of variance contribution of all model components. The proportion of variance contribution of a model component is calculated using its variance contribution and total variance.

\section{Results Analysis}

Shown in Table 4 is the established error budget at age 60 of the pipe model based on the correlated distribution. Each entity contributed different amounts of variance to different state variables.

For the projected state variable BA at age 60 (Table 4), the largest variance contributor is the initial BA itself, which contributes almost $42 \%$ variance to the final prediction. The second largest variance contributor is entity $\mathrm{C}$, which contributes $28.9 \%$ variance to prediction. Entity PSI $(\psi)$ contributes $12.88 \%$ variation to BA. These entities all concern initial basal area (BA), forest density $(\mathrm{C})$, and proportion of the basal area of the dead trees $(\psi)$. All the other entities 
individually contribute less than $3 \%$ variation to model prediction. The smallest variance contributors are entities TV, V1, and V2. Their variance contributions are 0 . They are entities concerning the volume of the forest. In the pipe model, they do not appear in the sub-model of $\mathrm{BA}$. The overall variance and coefficient of variation $(\mathrm{CV})$ of BA is 47.37 and $11 \%$, respectively.

For the projected state variable PL, the largest variance contributors are entities I and ALPHA $(\alpha)$. They contribute, respectively, $15.47 \%$ and $15.03 \%$ of variance. Entities LAMBDA $(\lambda)$, ZETA $(\zeta)$, and initial PL also have variance contributions larger than $10 \%$. These 5 entities concern complex environmental quality (I), maximum photosynthesis productivity $(\alpha)$, foliar dry matter $(\zeta)$, and pipe length ( $\lambda$ and PL), respectively. Entities BA, C, TV, V1, V2, and PSI $(\psi)$ contribute no variation to prediction of pipe length. These entities only contribute uncertainty to projected BA and TV. The overall variance and CV of PL are 2.06 and 6\%, respectively.

For the projected state variable TV, the largest variance contributor is the initial TV, which has $19.22 \%$ variance contribution. Entities I, ALPHA $(\alpha), \mathrm{C}$, and ZETA $(\zeta)$ individually contribute $9.6 \%$ to $12.3 \%$ variation to prediction of TV. These 4 entities concern environmental quality (I), maximum photosynthesis productivity $(\alpha)$, forest density $(\mathrm{C})$, and foliar dry matter $(\zeta)$, respectively. They are all major variance contributors to state variable BA or PL. The initial state variable TV is the larggest uncertainty contributor, which contributes about $19 \%$ uncertainty to the final prediction. The variance of prediction is 13349 , which is smaller than that obtained from observations, and the corresponding CV is $14 \%$.

The error budget built based on simulation using independent distributions is listed in Table 5. The difference in error budgets between correlated and independent cases are very large. Entity $\mathrm{I}$ is the largest variance contributor for all the three state variables. It contributes about $41 \%$ variation to the prediction of both PL and TV. This is at least two times the variation contribution of any other entity (Table 5). The variance contributions of the initial PL and TV to their corresponding predictions are less than 4\%. The overall variances of the predicted BA, PL, and TV are 55.7, 34.9, and 78496.9, respectively. For PL or TV, their variances of predictions are at least 5 times larger than those obtained using correlated distribution. The CV's of PL and TV are, respectively, $26.9 \%$ and $33 \%$, which make the predictions meaningless since the confidence intervals will be too wide and precision of predictions will be too low.

\section{Discussion and Conclusion}

Error budgets built based on correlated distribution estimated by rejection Bayesian sampling and improve Monte Carlo method can demonstrate realistic and reasonable uncertainty sources and their contributions. The error budget can also reflect the relationship among the entities of the pipe model and ecosystems. An error budget shows the importance and co-effects of the entities of the model.

The initial variation of the state variables of the pipe model is a major uncertainty source. Complex environmental quality, foliar dry matter, maximum photosynthesis productivity, selfthinning factor, and the scalar of new active pipe dry matter are the next important sources of uncertainty. The influence of the complex environmental quality and maximum photosynthesis productivity is almost the same for each state variable, although their variance contribution for 
each state variable is different. They are always the top five largest variance contributors. This reflected the biological and ecological roles of these entities of the model and ecosystem.

The assumption of independence of the distribution of the components is unrealistic and not suitable for ecosystem simulation and uncertainty analysis, even when the marginal distributions of all the components of a model are estimated with observations. In this study, given a variance smaller than its estimate for each entity of the pipe model, the overall variance from simulation and coefficients of variation are still very large for state variables PL or TV. The inflated variation changes the rank of variance contribution so that the contribution of the initial state variables becomes very small and unimportant. The over-estimated variation of projection caused by complex environmental quality makes the environment factor much more important than synthesis and productivity entities. This is not correct in biological and ecological theories. When a shorter interval and a smaller variance are assigned to each component of a model to reduce overall variation, it also changes the role of important components. The simulation outcome based on such reduced independent marginal distributions can not reflect the dynamics of real ecosystems.

\section{Summary}

Uncertainty analysis based on correlated distribution can build realistic and reasonable error budgets. The relationship between environment and productivity entities can be revealed in the reasonable error budgets. Initial state variables play an important role in contributing uncertainty to prediction. Uncertainty analysis based on independent distribution can provide much higher uncertainty, over-emphasize the importance of environment entities, and underestimate the importance of initial state variables and other productivity entities. Both the overall uncertainty and rank of uncertainty contributors are not reasonable and reliable. Bayesian inference, rejection sampling, and the improved Monte Carlo method are the bases of uncertainty analysis using correlation distribution. The new methods provided the possibility to do uncertainty analysis based on correlated distributions.

\section{Acknowledgement}

We are grateful to SERDP (Strategic Environmental Research and Development Program) for providing support.

\section{References}

Cox, N. D. 1977. Comparison of two uncertainty analysis methods. Nuclear Science and Engineering, 64:258-265.

Downing, D. J., R. H. Gardner, and F. O. Hoffman 1985. An Examination of response-surface methodologies for uncertainty analysis in assessment models. Technometrics. Vol.27(2):151-163.

Fang, S. 2000. Uncertainty analysis of biological nonlinear models based on Bayesian Estimation. Ph.D. Dissertation, University of Illinois at Urbana-Champaign, U.S.A.

Gardner, R.H., V.H. Dale, and R.V. O'Neill 1990. Error propagation and uncertainty in process modelling. In: R.K. Dixon, R.S. Meldahl, G.A. Ruark, and W.G. Warren, eds. Process modelling of forest growth responses to environmental stress. Timber Press. 
Gertner, G. Z. 1987. Approximating precision in simulation projections: an efficient alternative to Monte Carlo methods. Forest Science 33: 230-239.

Gertner, G. Z. 1991. Prediction bias and response surface curvature. Forest Science 37: 755-765.

Gertner, G. Z., P. Parysow and B. Guan 1996. Projection variance partitioning of a conceptual forest growth model with orthogonal polynomials. Forest Science 42: 474-486.

Gertner, G. Z., S. Fang, and J. P. Skovsgaard 1999. A Bayesian approach for estimating the parameters of a forest process model based on long-term growth data. Ecological Modelling 119: 249-265.

Hakkila, P. 1989. Utilization of residual forest biomass. Springer.

Jansen, M. J. W., W. A. H. Rossing, and R. A. Daamen 1994. Monte Carlo estimation of uncertainty contributions from several independent multivariate sources. In Proc. Congress Predictibility and Nonlinear Modelling in Natural Sciences and Economics, 5-7 April 1993, The Netherlands

Keesman, K. and G. V. Straten 1990. Identification and prediction propagation of uncertainty in models with bounded noise. INT. J. Control 49(6):2259-2269.

Madsen, S.F. and M. Heusèrr 1993. Volume and stem-taper functions for Norway spruce in Denmark. Forest and Landscape Research (Denmark) 1:51-78.

Matsumoto, K., T. Takeda, and T. Masuda , 1994. Approximate calculation method for 2 nd order S. C.. Journal of Nuclear Science and Technology 31 (11): 151-1159.

Morris, M. D. 1991. Factorial sampling plans for preliminary computational experiments. Technometrics 33(2):161-174.

Mowrer, H. T., and W. E. Frayer, 1986. Variance propagation in growth and yield projections. Can. J. For. Res. 16: 1196-1200.

Noor, A. K., Y. H. Kim, and J. M. Peters , 1994. Transverse shear stresses and their sensitivity coefficients in multilayered composite panels. AIAA Journal 32 (1): 1259-1269.

Rossing, W. A. H., M. J. W. Jansen, and R. A. Daaman, 1994. Uncertainty analysis applied to supervised control of aphids and brown rust in winter wheat. Part 2. Relative importance of different components of uncertainty. Agricultural systems 44: 449-460.

Sarma, M. A., K. K. Raju, and G. V. Rao, 1993. Prediction of structural behavior of plates after design modifications using sensitivity coefficients. Computers and structures 46 ( 1 ): 183 186.

Skovsgaard, J.P. 1997. Management of Sitka spruce without thinnings. Forskningsserien, The Research Series No. 19, Danish Forest and Landscape Research Institute.

Sobol, I. M. 1993. Sensitivity estimates for nonlinear mathematical models. Mathematical Modeling and Computational Experiments Vol.1(4):407-414.

Summers, J. K., H. T. Wilson, and J. Kou 1993. A method for quantifying the prediction uncertainty associated with water quality models. Ecological Modelling 65:161-176.

Valentine, H.T. 1985. Tree-growth models: derivations employing the pipe-model theory. Journal of Theoretical Biology 117:579-585.

Valentine, H.T. 1988. A carbon-balance model of stand growth: a derivation employing pipemodel theory and the self-thinning rule. Annals of Botany 62:389-396. 


\section{Appendix: Uncertainty analysis based on correlated distribution}

Fang (2000) proposed the following improved Monte Carlo method to build error budgets based on correlated distribution:

$$
\mathrm{E}\left\{\operatorname{var}\left[f\left(\theta_{\mathrm{i}}, \Theta_{\mathrm{i}}^{-}\right) \mid \Theta_{\mathrm{i}}^{-}\right]\right\}=\frac{1}{2} \cdot \frac{1}{\mathrm{~N}} \sum_{\mathrm{j}=1}^{\mathrm{N}}\left\{\left[f\left(\theta_{\mathrm{i}, 1, \mathrm{j}}, \Theta_{\mathrm{i}, \mathrm{j}}^{-}\right) \mid \Theta_{\mathrm{i}, \mathrm{j}}^{-}\right]-\left[f\left(\theta_{\mathrm{i}, 2, \mathrm{j}}, \Theta_{\mathrm{i}, \mathrm{j}}^{-}\right) \mid \Theta_{\mathrm{i}, \mathrm{j}}^{-}\right]\right\}^{2}
$$

where $f(\Theta)$ is the model, $\Theta=\left(\theta_{1}, \cdots, \theta_{\mathrm{q}}\right)^{\prime}$ is model component vector, $\operatorname{var}\left[f\left(\theta_{\mathrm{i}}, \Theta_{\mathrm{i}}^{-} \mid \Theta_{\mathrm{i}}^{-}\right)\right]$is the variance contribution of model component $\theta_{\mathrm{i}}, \Theta_{\mathrm{i}}^{-}=\left(\theta_{1}, \cdots, \theta_{\mathrm{i}-1}, \sim, \theta_{\mathrm{i}+1}, \cdots, \theta_{\mathrm{q}}\right)^{\prime}, \mathrm{N}$ is sample size. Using sampling scheme described in Figure 1, Eq.A1 will provide variance contribution of individual model components. Assume that the co-contribution of a model component is proportional to its individual contribution, the error budget of a model can be built based on Eq.A1. More details can be found in Fang (2000). 
Table 1. Definition of the entities (parameters) of the pipe model (from Gertner et al., 1996).

\begin{tabular}{|c|c|c|}
\hline Category & Parameter & Definition \\
\hline \multirow{3}{*}{$\begin{array}{c}\text { State } \\
\text { Variables }\end{array}$} & BA & total basal area of live trees at $1.3 \mathrm{~m}$ above ground $\left(\mathrm{m}^{2}\right)$ \\
\hline & PL & average active pipe length (from leaves to feeder roots) $(\mathrm{m})$ \\
\hline & TV & total woody volume (stems, branches, and coarse roots) $\left(\mathrm{m}^{3} / \mathrm{ha}\right)$ \\
\hline \multirow{4}{*}{ Pipe and } & AMAX & active basal area at $1.3 \mathrm{~m}$ above ground $\left(\mathrm{m}^{2} / \mathrm{ha}\right)$ \\
\hline & $\mathrm{BP}$ & $\begin{array}{l}\text { units of dry matter consumed per year for maintenance of a unit of active pipe } \\
\text { dry matter (1/year) }\end{array}$ \\
\hline & $\mathrm{I}$ & $\begin{array}{l}\text { scaling variable for annual dry matter production per unit of foliage dry matter } \\
\text { (unitless) }\end{array}$ \\
\hline & $\operatorname{LAMBDA}(\lambda)$ & proportion of new active pipe dry matter allocated to wood expansion (unitless) \\
\hline \multirow{2}{*}{ Basal Area } & $\mathrm{P}$ & units of woody dry matter per unit woody volume $\left(\mathrm{kg}\right.$ carbon $\left./ \mathrm{m}^{3}\right)$ \\
\hline & $\mathrm{RP}$ & $\begin{array}{l}\text { units of dry matter consumed in the construction of a new unit of woody dry } \\
\text { matter (unitless) }\end{array}$ \\
\hline Parameters & THETA $(\theta)$ & $\begin{array}{l}\text { proportion of the average active pipe length corresponding to the average length } \\
\text { of the deactivating pipes (unitless) }\end{array}$ \\
\hline \multirow{3}{*}{ Foliar } & $\operatorname{ALPHA}(\alpha)$ & $\begin{array}{l}\text { average units of substrate dry matter produced per year per unit of foliar dry } \\
\text { matter (1/year) }\end{array}$ \\
\hline & $\mathrm{BZ}$ & $\begin{array}{l}\text { units of dry matter consumed per year for maintenance of a unit of foliar dry } \\
\text { matter (1/year) }\end{array}$ \\
\hline & RZ & $\begin{array}{l}\text { units of dry matter consumed in the construction of a new unit of foliar dry } \\
\text { matter (unitless) }\end{array}$ \\
\hline \multirow[t]{2}{*}{ Parameters } & $\mathrm{TZ}$ & average final leaf age (years) \\
\hline & ZETA $(\zeta)$ & $\begin{array}{l}\text { units of foliar dry matter in midsummer per unit of active basal area (kg carbon } \\
\left./ \mathrm{m}^{2}\right)\end{array}$ \\
\hline Feeder & $\mathrm{BF}$ & $\begin{array}{l}\text { units of dry matter consumed per year for maintenance of a unit of feeder root } \\
\text { dry matter (1/year) }\end{array}$ \\
\hline Root & $\mathrm{F}$ & $\begin{array}{l}\text { units of feeder root dry matter in midsummer per unit of active basal area }(\mathrm{kg} \\
\left.\text { carbon } / \mathrm{m}^{2}\right)\end{array}$ \\
\hline \multirow[t]{2}{*}{ Parameters } & $\mathrm{RF}$ & $\begin{array}{l}\text { units of dry matter consumed in the construction of a new unit of feeder root dry } \\
\text { matter (unitless) }\end{array}$ \\
\hline & TF & average final feeder root age (years) \\
\hline \multirow{4}{*}{$\begin{array}{l}\text { Dead Tree } \\
\text { and Branch }\end{array}$} & $\mathrm{C}$ & $\begin{array}{l}\text { slope of the log-log relationship between number of trees versus tree of average } \\
\text { basal area (number of trees } / \mathrm{m}^{2} \text { ) }\end{array}$ \\
\hline & $\operatorname{PSI}(\psi)$ & $\begin{array}{l}\text { proportion of the total average basal area per tree corresponding to the average } \\
\text { basal area of dead trees (unitless) }\end{array}$ \\
\hline & V1 & $\begin{array}{l}\text { rate of volume lost to shedding of inactive pipe branches as a proportion of the } \\
\text { product of new active basal area and average active pipe length (unitless) }\end{array}$ \\
\hline & $\mathrm{V} 2$ & $\begin{array}{l}\text { rate of disused pipe volume lost to mortality as a proportion of the product of } \\
\text { inactive basal area lost to mortality and average active pipe length (unitless) }\end{array}$ \\
\hline
\end{tabular}


Table 2. Simple statistics of the observed data set.

\begin{tabular}{|c|c|c|c|c|}
\hline \multicolumn{2}{|c|}{ State Var.* } & $\mathrm{BA}\left(\mathrm{m}^{2}\right)$ & $\mathrm{PL}(\mathrm{m})$ & $\mathrm{TV}\left(\mathrm{m}^{3}\right)$ \\
\hline \multicolumn{2}{|c|}{ Sample Size } & \multicolumn{3}{|c|}{97} \\
\hline \multirow[t]{2}{*}{ Min. } & Age & \multicolumn{3}{|c|}{15} \\
\hline & State Var & 13.58 & 7.28 & 82.94 \\
\hline \multirow[t]{2}{*}{ Max. } & Age & \multicolumn{3}{|c|}{54} \\
\hline & State Var. & 55.76 & 21.50 & 881.12 \\
\hline \multirow[t]{2}{*}{ Mean } & Age & \multicolumn{3}{|c|}{34.2} \\
\hline & State Var & 42.87 & 14.39 & 520.52 \\
\hline \multicolumn{2}{|c|}{$\begin{array}{c}\text { Covariance } \\
\text { Matrix }\end{array}$} & $\begin{array}{l}90.54 \\
28.73 \\
1814.75\end{array}$ & $\begin{array}{c}12.92 \\
711.42\end{array}$ & 41641.74 \\
\hline
\end{tabular}

*State Var. represents state variables. 
Table 3. Truncated normal distribution of the pipe model used for building error budgets.

\begin{tabular}{|c|c|c|c|c|c|c|}
\hline$*$ Distribution & \multicolumn{2}{|c|}{ Bounds } & \multicolumn{2}{|c|}{$* *$ Independent } & \multicolumn{2}{|c|}{$* * *$ Prior } \\
\hline Entity & Lower & Upper & Mean & $\begin{array}{c}\text { Standard } \\
\text { Deviation }\end{array}$ & Mean & $\begin{array}{c}\text { Standard } \\
\text { Deviation }\end{array}$ \\
\hline $\mathrm{BA}\left(\mathrm{m}^{2} / \mathrm{ha}\right)$ & 30.0 & 57.4 & 43.64 & 3.38 & 43.64 & 4.70 \\
\hline $\mathrm{PL}(\mathrm{m})$ & 10.0 & 16.0 & 13.00 & 0.774 & 13.00 & 1.08 \\
\hline $\mathrm{TV}\left(\mathrm{m}^{3}\right)$ & 300.0 & 634.0 & 464.35 & 51.71 & 464.35 & 76.95 \\
\hline $\operatorname{AMAX}\left(\mathrm{m}^{2} / \mathrm{ha}\right)$ & 20.0 & 32.252 & 28.48054 & 2.03 & 26.126 & 8.0 \\
\hline BP (per year) & 0.018 & 0.024 & 0.02098 & 0.00001 & 0.021 & 0.0063 \\
\hline I & 0.2 & 1.0 & 0.58422 & 0.0807 & 0.6 & 0.18 \\
\hline$\lambda$ & 0.55 & 0.95 & 0.75957 & 0.0712 & 0.75 & 0.23 \\
\hline $\mathrm{P}\left(\mathrm{kg} \mathrm{c} / \mathrm{m}^{3}\right)$ & 195 & 255 & 221.2586 & 12.59 & 225 & 66.0 \\
\hline $\mathrm{RP}$ & 0.12 & 0.24 & 0.17896 & 0.0237 & 0.18 & 0.054 \\
\hline$\theta$ & 0.55 & 0.95 & 0.8826 & 0.0359 & 0.75 & 0.23 \\
\hline$\alpha$ & 5.0 & 8.2 & 6.49595 & 0.625 & 6.6 & 2.0 \\
\hline BZ (per year) & 0.35 & 0.60 & 0.47474 & 0.0510 & 0.48 & 0.15 \\
\hline $\mathrm{RZ}$ & 0.12 & 0.24 & 0.1804 & 0.0233 & 0.18 & 0.054 \\
\hline TZ (year) & 5.5 & 8.5 & 6.95784 & 0.615 & 7 & 2.1 \\
\hline$\zeta\left(\mathrm{kg} \mathrm{c} / \mathrm{m}^{2}\right)$ & 150 & 264 & 204.4994 & 22.66 & 208 & 62.4 \\
\hline BF (per year) & 0.018 & 0.024 & 0.02095 & 0.00001 & 0.021 & 0.0063 \\
\hline $\mathrm{F}\left(\mathrm{kg} \mathrm{c} / \mathrm{m}^{2}\right)$ & 302.3 & 522.3 & 413.9908 & 45.09 & 412.3 & 150 \\
\hline $\mathrm{RF}$ & 0.12 & 0.24 & 0.18044 & 0.0236 & 0.18 & 0.054 \\
\hline TF (year) & 1.5 & 2.5 & 1.9931 & 0.200 & 2 & 0.6 \\
\hline $\mathrm{C}$ & 0.65 & 0.95 & 0.80643 & 0.0611 & 0.8 & 0.24 \\
\hline$\psi$ & 0.3 & 0.9 & 0.59117 & 0.101 & 0.6 & 0.18 \\
\hline V1 & 0.075 & 0.225 & 0.12545 & 0.0255 & 0.15 & 0.045 \\
\hline $\mathrm{V} 2$ & 0.60 & 0.90 & 0.69522 & 0.0506 & 0.75 & 0.23 \\
\hline
\end{tabular}

*Both distributions share the same bounds. The state variables BA, PL, and TV are estimated using observations of Norway spruce from Denmark at the ages of 28 to 32 years.

**The mean vector is estimated by rejection Bayesian estimation with the prior in ***, standard deviation is 0.7416 times of the estimated standard deviation.

***Prior for rejection Bayesian estimation. The standard deviation of all entities, except BA, PL, and TV, is computed based on a coefficient of variation of $30 \%$. 
Table 4. Error budget of the pipe model based on correlated distribution for Norway spruce in Denmark. $\operatorname{Var}\left[f\left(\theta_{\mathrm{i}}, \Theta_{\mathrm{i}}^{-}\right) \mid \Theta_{\mathrm{i}}^{-}\right]$, variance contribution of $\theta_{\mathrm{i}}$, is represented by $\operatorname{Var}\left[f\left(\theta_{\mathrm{i}}, \dot{)}\right) \mid \cdot\right]$.

Proportion is the proportion of the variability of the projected state variable at age 60 years due to the entity.

\begin{tabular}{|c|c|c|c|c|c|c|}
\hline Projected & \multicolumn{2}{|c|}{$\mathrm{BA}$} & \multicolumn{2}{|c|}{ PL } & \multicolumn{2}{|c|}{ TV } \\
\hline Entity & $\operatorname{Var}[f(\theta .) \mid. \cdot]$ & Proportion & $\operatorname{Var}[f(\theta . \cdot) \mid \cdot]$ & Pronortion & $\operatorname{Var}[f(\theta-) \mid. \cdot]$ & Pronortion \\
\hline $\mathrm{BA}$ & 21.468 & $41.89 \%$ & 0.000 & $0.00 \%$ & 0.0 & $0.00 \%$ \\
\hline PL & 0.794 & $1.55 \%$ & 0.803 & $10.66 \%$ & 75.7 & $0.31 \%$ \\
\hline TV & 0.000 & $0.00 \%$ & 0.000 & $0.00 \%$ & 4752.9 & $19.22 \%$ \\
\hline AMAX & 0.722 & $1.41 \%$ & 0.000 & $0.00 \%$ & 1000.6 & $4.05 \%$ \\
\hline BP & 0.058 & $0.11 \%$ & 0.060 & $0.79 \%$ & 142.4 & $0.58 \%$ \\
\hline I & 1.313 & $2.56 \%$ & 1.164 & $15.45 \%$ & 3051.5 & $12.34 \%$ \\
\hline$\lambda$ & 1.125 & $2.19 \%$ & 0.989 & $13.13 \%$ & 256.7 & $1.04 \%$ \\
\hline$P$ & 0.382 & $0.74 \%$ & 0.508 & $6.75 \%$ & 1274.6 & $5.15 \%$ \\
\hline RP & 0.044 & $0.09 \%$ & 0.062 & $0.82 \%$ & 155.6 & $0.63 \%$ \\
\hline$\theta$ & 0.062 & $0.12 \%$ & 0.377 & $5.01 \%$ & 8.3 & $0.03 \%$ \\
\hline$\alpha$ & 1.185 & $2.31 \%$ & 1.132 & $15.02 \%$ & 2863.0 & $11.58 \%$ \\
\hline $\mathrm{BZ}$ & 0.214 & $0.42 \%$ & 0.212 & $2.81 \%$ & 519.2 & $2.10 \%$ \\
\hline RZ & 0.002 & $0.00 \%$ & 0.002 & $0.03 \%$ & 3.1 & $0.01 \%$ \\
\hline $\mathrm{TZ}$ & 0.021 & $0.04 \%$ & 0.023 & $0.31 \%$ & 54.8 & $0.22 \%$ \\
\hline$\zeta$ & 0.959 & $1.87 \%$ & 0.932 & $12.37 \%$ & 2394.3 & $9.68 \%$ \\
\hline $\mathrm{BF}$ & 0.002 & $0.00 \%$ & 0.002 & $0.03 \%$ & 1.5 & $0.01 \%$ \\
\hline $\mathrm{F}$ & 0.771 & $1.50 \%$ & 0.623 & $8.27 \%$ & 1498.8 & $6.06 \%$ \\
\hline RF & 0.074 & $0.14 \%$ & 0.058 & $0.76 \%$ & 139.4 & $0.56 \%$ \\
\hline TF & 0.639 & $1.25 \%$ & 0.587 & $7.79 \%$ & 1499.0 & $6.06 \%$ \\
\hline $\mathrm{C}$ & 14.819 & $28.91 \%$ & 0.000 & $0.00 \%$ & 2907.6 & $11.76 \%$ \\
\hline$\psi$ & 6.599 & $12.88 \%$ & 0.000 & $0.00 \%$ & 1333.3 & $5.39 \%$ \\
\hline V1 & 0.000 & $0.00 \%$ & 0.000 & $0.00 \%$ & 340.0 & $1.38 \%$ \\
\hline $\mathrm{V} 2$ & 0.000 & $0.00 \%$ & 0.000 & $0.00 \%$ & 454.0 & $1.84 \%$ \\
\hline Total & 51.251 & $100.00 \%$ & 7.533 & $100.00 \%$ & 24726.2 & $100.00 \%$ \\
\hline Overall & 47.368 & & 2.063 & & 13349.0 & \\
\hline $\mathrm{CV}^{*}$ & $11 \%$ & & $6 \%$ & & $14 \%$ & \\
\hline
\end{tabular}

$* \mathrm{CV}$ represents Coefficient of variation. 
Table 5. Error budget of the pipe model based on independent distribution for Norway spruce in Denmark. $\operatorname{Var}\left[f\left(\theta_{\mathrm{i}}, \Theta_{\mathrm{i}}^{-}\right) \mid \Theta_{\mathrm{i}}^{-}\right]$, variance contribution of $\theta_{\mathrm{i}}$, is represented by $\operatorname{Var}\left[f\left(\theta_{\mathrm{i}},\right)_{\mid} \cdot\right]$.

\begin{tabular}{|c|c|c|c|c|c|c|}
\hline State & \multicolumn{2}{|l|}{$\mathrm{BA}$} & \multicolumn{2}{|l|}{ PL } & \multicolumn{2}{|c|}{$\mathrm{TV}$} \\
\hline Entity & $\operatorname{Var}\left[f\left(\theta_{\mathrm{i}}, \dot{)}\right) \cdot\right]$ & Proportion & $\operatorname{Var}\left[f\left(\theta_{i}, \cdot\right) \mid \cdot\right]$ & Proportion & $\operatorname{Var}\left[f\left(\theta_{\mathrm{i}},\right)^{\prime} \mid \cdot\right]$ & Proportion \\
\hline $\mathrm{BA}$ & 11.560 & $19.37 \%$ & 0.000 & $0.00 \%$ & 0.0 & $0.00 \%$ \\
\hline $\mathrm{PL}$ & 0.393 & $0.66 \%$ & 0.386 & $1.10 \%$ & 34.4 & $0.04 \%$ \\
\hline $\mathrm{TV}$ & 0.000 & $0.00 \%$ & 0.000 & $0.00 \%$ & 2674.8 & $3.34 \%$ \\
\hline AMAX & 0.920 & $1.54 \%$ & 0.000 & $0.00 \%$ & 1723.8 & $2.15 \%$ \\
\hline $\mathrm{BP}$ & 0.000 & $0.00 \%$ & 0.000 & $0.00 \%$ & 0.0 & $0.00 \%$ \\
\hline $\mathrm{I}$ & 12.574 & $21.07 \%$ & 14.538 & $41.22 \%$ & 33735.0 & $42.15 \%$ \\
\hline$\lambda$ & 4.414 & $7.39 \%$ & 4.333 & $12.28 \%$ & 1084.9 & $1.36 \%$ \\
\hline$P$ & 0.308 & $0.52 \%$ & 0.582 & $1.65 \%$ & 1328.6 & $1.66 \%$ \\
\hline RP & 0.025 & $0.04 \%$ & 0.055 & $0.16 \%$ & 131.3 & $0.16 \%$ \\
\hline$\theta$ & 0.175 & $0.29 \%$ & 0.807 & $2.29 \%$ & 16.5 & $0.02 \%$ \\
\hline$\alpha$ & 5.842 & $9.79 \%$ & 6.698 & $18.99 \%$ & 15819.8 & $19.76 \%$ \\
\hline $\mathrm{BZ}$ & 0.115 & $0.19 \%$ & 0.122 & $0.35 \%$ & 286.5 & $0.36 \%$ \\
\hline $\mathrm{RZ}$ & 0.002 & $0.00 \%$ & 0.000 & $0.00 \%$ & 1.2 & $0.00 \%$ \\
\hline $\mathrm{TZ}$ & 0.012 & $0.02 \%$ & 0.012 & $0.03 \%$ & 26.4 & $0.03 \%$ \\
\hline$\zeta$ & 4.628 & $7.75 \%$ & 6.012 & $17.04 \%$ & 13938.7 & $17.41 \%$ \\
\hline $\mathrm{BF}$ & 0.000 & $0.00 \%$ & 0.000 & $0.00 \%$ & 0.0 & $0.00 \%$ \\
\hline $\mathrm{F}$ & 1.281 & $2.15 \%$ & 0.952 & $2.70 \%$ & 2289.5 & $2.86 \%$ \\
\hline $\mathrm{RF}$ & 0.037 & $0.06 \%$ & 0.030 & $0.08 \%$ & 68.1 & $0.09 \%$ \\
\hline TF & 0.759 & $1.27 \%$ & 0.745 & $2.11 \%$ & 1780.5 & $2.22 \%$ \\
\hline $\mathrm{C}$ & 11.332 & $18.99 \%$ & 0.000 & $0.00 \%$ & 2771.8 & $3.46 \%$ \\
\hline$\psi$ & 5.308 & $8.89 \%$ & 0.000 & $0.00 \%$ & 1249.2 & $1.56 \%$ \\
\hline $\mathrm{V} 1$ & 0.000 & $0.00 \%$ & 0.000 & $0.00 \%$ & 452.7 & $0.57 \%$ \\
\hline $\mathrm{V} 2$ & 0.000 & $0.00 \%$ & 0.000 & $0.00 \%$ & 627.4 & $0.78 \%$ \\
\hline Total & 59.685 & $100.00 \%$ & 35.273 & $100.00 \%$ & 80040.9 & $100.00 \%$ \\
\hline Overall & 55.745 & & 34.925 & & 78496.9 & \\
\hline $\mathrm{CV}^{*}$ & $12 \%$ & & $26 \%$ & & $33 \%$ & \\
\hline
\end{tabular}

$* \mathrm{CV}$ represents Coefficient of variation. 


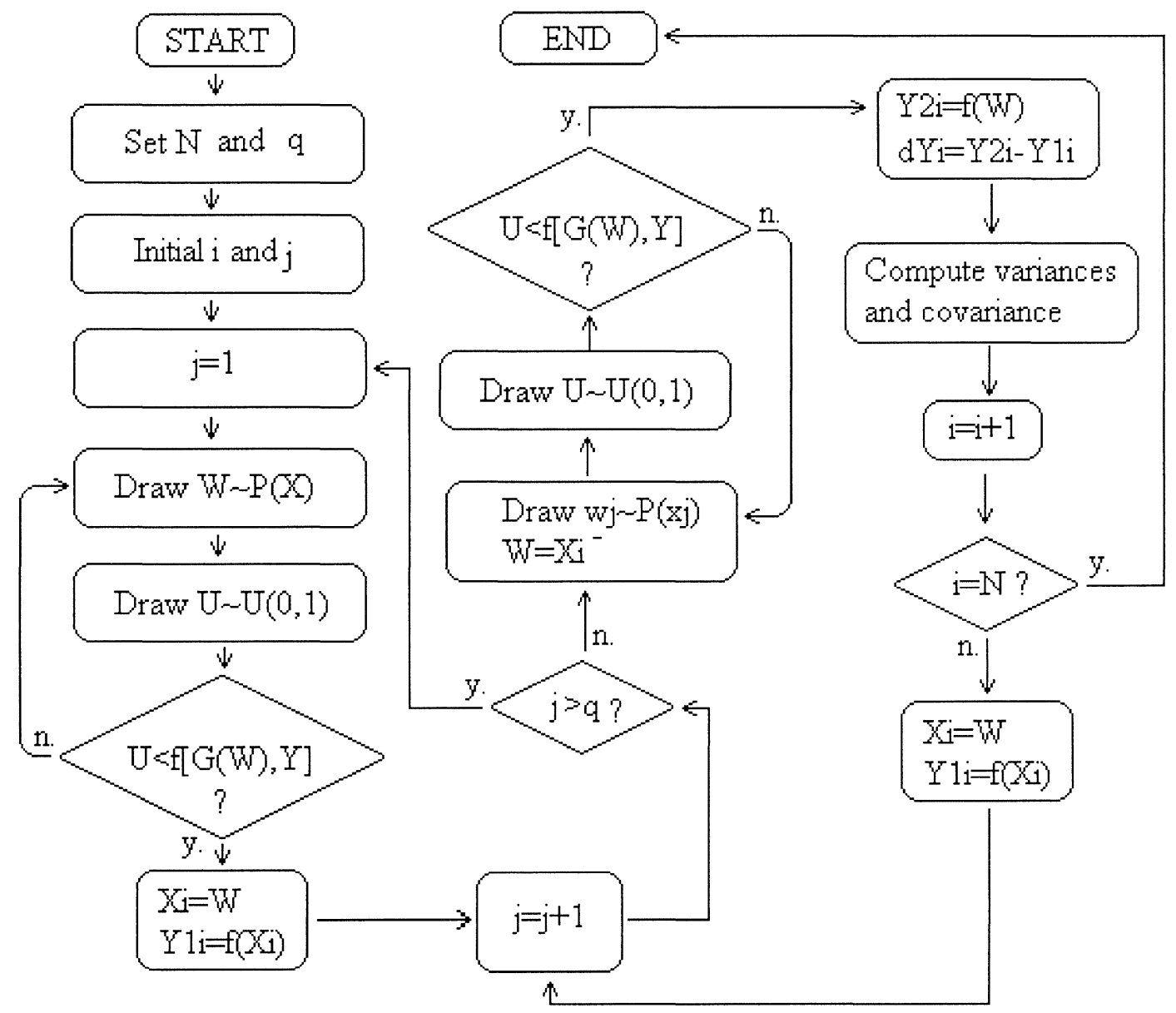

Figure 1. Diagram of the uncertainty analysis. $\mathrm{N}$ is the sample size, $\mathrm{q}$ is the total number of model components, $P(X)$ is the prior distribution of model components, equation $f[G(W), Y]$ is the envelope function in rejection sampling, computation of variance contribution refers to Appendix, $\mathrm{Xi}=\mathrm{X}_{\mathrm{i}}$, and $\mathrm{Xi}^{-}=\mathrm{X}_{\mathrm{i}}^{-}=\left(\mathrm{x}_{\mathrm{i}, 1}, \cdots, \mathrm{x}_{\mathrm{i}, \mathrm{j}-1}, \mathrm{w}_{\mathrm{j}}, \mathrm{x}_{\mathrm{i}, \mathrm{j}+1}, \cdots, \mathrm{x}_{\mathrm{i}, \mathrm{q}}\right)^{\prime}$. 